\title{
ARTIGOS
}

Submetido 11.07.2019. Aprovado 14.04.2020

Avaliado pelo sistema double blind review. Editor Científico convidado: Bolívar Godinho

Versão original

DOI: http://dx.doi.org/10.1590/So034-759020200505

\section{MÁS (BOAS) NOTÍCIAS E POSTERGAÇÃO (ANTECIPAÇÃO) DE DIVULGAÇÃO DE DEMONSTRAÇÕES FINANCEIRAS}

\author{
Bad (good) news and delay (anticipation) of financial statements' disclosure \\ Malas (buenas) noticias y postergación (anticipación) de divulgación de \\ estados financeiros
}

\begin{abstract}
RESUMO
Gestores de companhias possuem discricionariedade sobre o momento de divulgação dos resultados contábeis das companhias, levando a literatura a investigar potenciais determinantes da tempestividade da evidenciação. Nesse sentido, o objetivo deste estudo foi o de avaliar se o tipo de notícia a ser divulgada é fator que influencia a antecipação ou postergação da divulgação de informações ao mercado. Com base em dados de companhias abertas brasileiras listadas na B3, entre 2010 e 2016, foi implementada uma estratégia de se avaliar, por meio de regressão linear e logística, se o tipo de notícia está relacionado com a decisão do momento da publicação das demonstrações contábeis. As evidências encontradas indicam que as más (boas) estão relacionadas com a postergação (antecipação) da divulgação dos resultados contábeis trimestrais das companhias. Os resultados, portanto, contribuem com a literatura de evidenciação no Brasil e indicam que postergações estão associadas à divulgação de notícias negativas.
\end{abstract}

PALAVRAS-CHAVE | Evidenciação, tipo de notícia, tempestividade, data de divulgação, dicricionariedade.

\begin{abstract}
Managers have discretion over the timing of accounting information disclosure; existing literature has investigated the potential determinants regarding this choice. Thus, this study aimed to evaluate whether the type of accounting information is a factor that influences the anticipation of its disclosure to external users. The dataset comprises information provided by Brazilian companies listed on the Brasil Bolsa Balcão (B3) between 2010 and 2016. The research employed linear regression and the logistic regression model to evaluate whether type of news is a determinant for the timing of financial disclosures. Empirical evidence indicates that the nature of information (i.e., good or bad news) is related to the time taken (i.e., postponement or anticipation) in disclosing quarterly accounting figures of companies. Overall, our results contribute to the disclosure literature in Brazil and indicate that postponements are associated with the disclosure of negative news.
\end{abstract}

KEYWORDS I Disclosure, type of news, timeliness, disclosure date, discretion.

ANDERSON BRITO VIVAS ${ }^{1}$

andersonvivas@gmail.com

0000-0002-7630-5404

FELIPE RAMOS FERREIRA ${ }^{1}$

felipe.ramos@fucape.br

0000-0002-0469-9176

FÁBIO MORAES DA COSTA ${ }^{1}$

fabio@fucape.br

0000-0002-2098-4006

${ }^{1}$ Fucape Business School, Programa de Mestrado Profissional em Ciências Contábeis, Vitória, ES, Brasil

\section{RESUMEN}

Los gerentes tienen la facultad de decidir el momento oportuno de la divulgación de los resultados contables de las compañías, lo que lleva a la literatura a investigar los determinantes potenciales del momento de la divulgación. En ese sentido, el objetivo de este estudio fue evaluar si el tipo de noticias que se divulgarán es un factor que influye en la anticipación o el aplazamiento de la divulgación de información al mercado. Con base en datos de empresas brasileñas que cotizan en la B3 entre 2010 y 2016, se implementó una estrategia para evaluar, a través de regresión logística y lineal, si el tipo de noticias se relaciona con la decisión del momento de la publicación de los estados financieros. La evidencia indica que las malas (buenas) noticias están relacionadas con el aplazamiento (anticipación) de la divulgación de los resultados contables trimestrales de las compañías. Los resultados, por lo tanto, contribuyen a la literatura de divulgación en Brasil e indican que los aplazamientos están asociados con la divulgación de noticias negativas.

PALABRAS CLAVE I Divulgación, tipo de noticias, momento oportuno, fecha de divulgación, dicreción. 


\section{INTRODUÇÃO}

De acordo com Beyer, Cohen, Lys e Walther (2010), a informação contábil desempenha dois papéis relevantes em economias de mercado: permitir que os provedores de capital avaliem o potencial de retorno das oportunidades de investimento e que monitorem o uso de seu próprio capital. Para Bagnoli, Kross e Watts (2002), a utilidade da informação contábil não está relacionada apenas à sua natureza e ao seu conteúdo, mas também ao momento em que é divulgada, ou seja, se é tempestiva. Informações relevantes aos participantes do mercado podem não ter utilidade caso não sejam divulgadas tempestivamente ao público. Portanto, a qualidade das informações divulgadas deve levar em conta a tempestividade com que são disponibilizadas aos usuários.

A literatura internacional tem explorado a tempestividade da divulgação de informações, com foco em seus determinantes. Os estudos (Bagnoli et al., 2002; Haw, Qi, \& Wu, 2000) sugerem que, quando há a postergação da divulgação de informações em relação à data esperada pelo mercado, é provável que o relatório divulgado seja objeto de más notícias. Tal temática ainda não foi explorada no Brasil, pois a literatura nacional não levou em conta a tempestividade em relação à data esperada de divulgação pelo mercado, e sim em relação aos dias corridos da data base das demonstrações contábeis e à data de divulgação (Barcellos, Costa, \& Laurence, 2014; Kirch, Lima, \& Terra, 2012; Paixão, Avelino, \& Takamatsu, 2017).

A metodologia aplicada neste estudo diferencia-se de várias formas das abordagens utilizadas em pesquisas anteriores com foco no mercado brasileiro, principalmente no que tange a análise entre postergação/adiantamento na entrega das informações e defasagem da entrega das demonstrações contábeis. É razoável acreditar que as empresas mantenham um padrão de divulgação das demonstrações contábeis e que respeitem esse padrão em condições normais de divulgação, comportamento esse explorado em diversas pesquisas baseadas em naive models (Begley \& Ficher, 1998; Boulland \& Dessaint, 2017; Givoly \& Palmon, 1982). Além disso, analisando a postergação ou adiantamento na entrega das informações contábeis, é possível analisar e entender a decisão dos gestores em relação ao momento da divulgação e como os resultados apresentados podem influenciar essa decisão.

Com base no exposto nos parágrafos anteriores, o propósito deste trabalho é o de investigar se o tipo de notícia (boa ou má) é um dos determinantes da postergação ou adiantamento da entrega da demonstração contábil, em relação à data esperada de divulgação (baseado em naive model) por empresas brasileiras listadas na B3.

O fato de a postergação/adiantamento na entrega das demonstrações contábeis ao mercado ser um tema pouco abordado nas pesquisas acadêmicas desenvolvidas com base no mercado acionário brasileiro aumenta a relevância do assunto, o qual é debatido pelos participantes do referido mercado. Nota-se ainda que, com o processo de desenvolvimento do mercado de capitais brasileiro, é necessária a evolução de modelos capazes de auxiliar a antecipação dos tipos de notícias a serem divulgadas pelas empresas de capital aberto.

A amostra foi formada por 5.356 divulgações trimestrais e anuais de empresas listadas na B3, do período compreendido entre os anos de 2010 e 2016. As datas de divulgação das empresas foram coletadas manualmente. Foram desconsiderados na análise os trimestres em que houve reapresentação das demonstrações contábeis, bem como a data estimada de divulgação para o exercício seguinte. Foi considerada como data esperada para entrega das informações contábeis ao mercado o mesmo dia da semana utilizado para a divulgação no período correspondente do ano imediatamente anterior, mesma abordagem utilizada em outros trabalhos da literatura internacional (Bagnoli et al., 2002; Boulland \& Dessaint, 2017). Para a tipificação da notícia, considerou-se que as empresas que apresentaram resultado líquido superior (inferior) ao resultado líquido do mesmo período do ano anterior apresentaram boas notícias (más notícias), objetivo esse apontado pelos executivos como o mais importante para o lucro trimestral (Graham, Harvey, \& Rajgopal, 2005).

Os resultados encontrados sugerem que as empresas com más notícias (boas notícias) postergam (antecipam) a divulgação das informações contábeis em relação às datas esperadas. Adicionalmente, também foram encontradas evidências empíricas de que o tamanho da empresa, o endividamento e o fato de a empresa já ter postergado no período anterior a entrega da informação contábil também influenciam a divulgação das demonstrações contábeis atuais.

Esta pesquisa contribui para o avanço da literatura de evidenciação e divulgação no Brasil, mais especificamente no que tange à relação entre a postergação ou o adiantamento da entrega dessas informações quando comparada à data esperada pelos participantes do mercado e ao tipo de notícia divulgada. Contribui, em ordem prática, com os participantes de mercado (investidores, gestores, analistas de mercado etc.), ajudando-os a entender a referida relação entre a postergação ou antecipação da entrega das demonstrações contábeis e o desempenho das empresas, além da melhor 
compreensão acerca dos mecanismos de divulgação utilizados pelas empresas no Brasil.

\section{REFERENCIAL TEÓRICO}

De acordo com Dantas, Zendersky, Santos e Niyama (2008), o objetivo da Contabilidade é fornecer informações relevantes aos investidores e credores. Para que as demonstrações contábeis sejam relevantes aos seus usuários, elas devem possuir as divulgações necessárias para refletir adequadamente ao leitor o momento econômico e financeiro da companhia analisada.

Segundo Healy e Palepu (2001), a divulgação é fundamental para o funcionamento eficiente de um mercado de capitais. As empresas realizam a divulgação por meio de relatórios financeiros regulamentados, incluindo as demonstrações financeiras, notas explicativas, discussão e análise de gerenciamento e outros registros exigidos pela regulação. Além disso, algumas empresas realizam divulgações voluntárias, que podem incluir, sem limitação, previsões de gerenciamento, apresentações para analistas, audioconferências, comunicados de imprensa e sites na internet.

Verrecchia (2001) e Dye (2001) argumentam que um dos fatores relacionados à teoria da divulgação pode estar ligado a questões endógenas, ou seja, a decisões da firma/gestor de divulgar ou não uma informação. Essa divulgação, baseada em julgamentos, busca entender quais fatores influenciam a decisão da firma/gestor sobre sua estratégia de divulgação. Givoly e Palmon (1982) representam um dos trabalhos precursores relacionados aos determinantes do momento da divulgação da informação contábil e encontram evidências de que as empresas tendem a postergar a divulgação de más notícias no ambiente americano.

Em pesquisa realizada por Kross e Schroeder (1984) no mercado norte-americano, foi analisada a associação entre o tipo de notícia relatada e a data de divulgação das informações contábeis trimestrais, bem como o impacto da data de divulgação nos retornos anormais sobre os valores das ações. Os retornos anormais das empresas que divulgaram cedo foram significativamente maiores do que os retornos das empresas que anunciaram tarde.

Já Bagnoli et al. (2002) analisaram o desempenho das empresas em que a administração ultrapassa sua própria data esperada de divulgação (capturada por empresa especializada); os resultados apontam que o relatório divulgado apresenta más notícias e que quanto maior o atraso, pior a notícia. Em 91\% dos atrasos, os analistas de mercado não atualizam a estimativa de resultado por ação em resposta ao atraso na divulgação. No entanto, os retornos médios nos dias seguintes de negociação em relação à data esperada do relatório são negativos.

Trueman (1990) analisou duas explicações alternativas para a variação no preço da ação quando o relatório de divulgação é atrasado ou adiantado. Ambas as análises tinham como base a premissa de que algumas empresas com ganhos desfavoráveis aumentam sua receita reportada por meio de gerenciamento de resultados. Em um caso, o gerenciamento de resultados exigiu um atraso no relatório, enquanto no outro caso um atraso foi causado pelo desejo do gerente de observar primeiro os ganhos de outras empresas. Ambos os casos analisados conduzem a reações por parte do mercado positivas quando os relatórios são adiantados, e negativas quando são atrasados, em conformidade com os achados empíricos anteriores.

Chen, Cheng e Gao (2005) avaliaram a data de anúncio de resultados no mercado chinês, um dos poucos mercados do mundo com um período de divulgação de quatro meses. Os resultados apontam que as empresas que fazem divulgações antecipadas tendem a surpreender o mercado, como indicado pelas maiores reações em relação ao volume de negociações e ao preço das ações. Em contrapartida, anúncios posteriores são mais previsíveis, como indicado pelas menores reações em relação ao volume de negociação e ao preço das ações.

Ainda em relação ao mercado chinês, Haw et al. (2000) concluíram que empresas com boas notícias reportam seus resultados antes das empresas com más notícias. Em conformidade com pesquisas anteriores, concluíram, também, que as empresas aceleram ou atrasam a divulgação dos resultados em relação ao seu padrão de divulgação, dependendo do tipo de notícia a ser divulgada.

Sengupta (2004) investigou os fatores determinantes que levaram as empresas a optar por liberar seus resultados trimestrais relativamente mais rápido se comparadas com outras. Os resultados foram baseados em dados do mercado norte-americano, no período de 1995 a 2000, e indicaram que a natureza da base de investidores, os custos de litígio, a complexidade contábil e o tipo de notícia estão diretamente relacionados ao atraso reportado, que foi definido no estudo com base no número de dias corridos após o encerramento do trimestre.

No mercado brasileiro, Kirch et al. (2012) investigaram os fatores determinantes da defasagem (período transcorrido entre a data de encerramento do exercício e a data de divulgação dos resultados) na divulgação das demonstrações contábeis. Os resultados encontrados apontam que empresas com demonstrações contábeis consolidadas e/ou que apresentem 
prejuízo possuem maior defasagem na entrega das informações contábeis aos participantes do mercado, ou seja, divulgam as informações com mais dias corridos após a data base em relação às demais empresas.

Com base na discussão apresentada e em linha com Haw et al. (2000) em pesquisa realizada no mercado emergente chinês, o presente estudo apresenta a seguinte hipótese de pesquisa:

H1: Empresas com más (boas) notícias postergam (antecipam) a divulgação das informações contábeis em relação às datas esperadas.

\section{METODOLOGIA DE PESQUISA E AMOSTRA}

Para realização deste estudo, foram utilizadas todas as sociedades por ações abertas listadas na B3, considerando a obrigatoriedade da divulgação das demonstrações contábeis por tais companhias. Foram analisadas as informações trimestrais e as demonstrações financeiras anuais divulgadas do período de 2010 a 2016.

Para fins desta pesquisa, considera-se como data de divulgação aquela registrada para cada companhia nas demonstrações contábeis ativas na página eletrônica da Comissão de Valores Mobiliários (CVM - www.cvm.gov.br). Os dados referentes à data de entrega das informações contábeis foram coletados manualmente, e os demais dados utilizados foram extraídos da base de dados Economática ${ }^{\circledR}$.

Foram desconsiderados da base de dados os períodos em que, porventura, as empresas tenham reapresentado suas demonstrações contábeis, tendo em vista que a reapresentação pode alterar o tipo de notícia contida nas referidas demonstrações. Caso tenha ocorrido a reapresentação da demonstração contábil no período, torna-se inviável a estimativa de data de divulgação das referidas demonstrações em períodos subsequentes. Adicionalmente, também foram excluídos os setores de Fundos, Finanças e Seguros, por apresentarem tratamento contábil diferente dos demais setores (exemplo: classificação de contas de resultado). A conciliação da base de pesquisa utilizada por este estudo está apresentada na Tabela 1.

Diversos métodos podem ser utilizados para classificar o tipo de notícia divulgada pelas empresas como "boa notícia" ou "má notícia”, como bater ou superar o consenso da previsão dos analistas ou bater ou superar o lucro do mesmo trimestre do ano anterior. Para fins deste estudo, devido ao baixo número de analistas que cobrem as empresas brasileiras e à dificuldade de obtenção de base histórica das previsões de analistas do mercado brasileiro, definiu-se como divulgação de boa notícia as empresas que apresentaram resultado líquido superior ao resultado líquido do período comparativo e como má notícia as que divulgarem resultado líquido inferior ao período comparativo. O método utilizado está em linha com o trabalho realizado por Graham et al. (2005), que, baseado em uma pesquisa feita com diversos executivos, identificarem ser esse o objetivo (meta) mais importante para lucros trimestrais.

\section{Tabela 1. Conciliação da base de dados}

\begin{tabular}{l|c}
\hline Número de observações inicial (empresa-trimestre) & 13.691 \\
\hline $\begin{array}{l}\text { Dados comparativos inexistentes } \\
\left(2009 \text { ou } 1^{0} \text { ano listada) }\right.\end{array}$ & $(-) 2.026$ \\
\hline Exclusão das reapresentações & $(-) 3.149$ \\
\hline Exclusão dos períodos seguintes às reapresentações & $(-) 2.038$ \\
\hline Exclusão dos setores de Fundos, Finanças e Seguros & $(-) 595$ \\
\hline Exclusão de dados faltantes para os modelos & $(-) 527$ \\
\hline Número de observações final (empresa-trimestre) & 5.356 \\
\hline
\end{tabular}

As comparações entre os modelos de expectativas de data de divulgação realizadas por Bagnoli et al. (2002) sugerem que os participantes de mercado possuem melhores expectativas das datas de divulgação do que aquelas realizadas por modelos de estimativa (naive models). A data de divulgação estimada no mesmo dia da semana do exercício anterior, por sua vez, apresenta maior precisão quando comparada à data estimada, com base no mesmo dia do exercício anterior.

Considerando a inexistência de base histórica com expectativa dos participantes do mercado em relação à data de divulgação das empresas brasileiras, para fins desta pesquisa, e em linha com o teste de eficácia apresentado por Bagnoli et al. (2002), a data esperada de divulgação das informações é o mesmo dia da semana de divulgação do ano anterior. Por exemplo, se a divulgação de determinado exercício ocorreu no dia 12 de março de 2015, uma quinta-feira, a data esperada de divulgação do exercício seguinte é o dia 10 de março de 2016, também uma quinta-feira da mesma semana do mês. Caso a empresa divulgue seu resultado após a data esperada, então considera-se que há uma postergação na entrega das informações contábeis aos participantes do mercado. Caso a publicação ocorra antes da data esperada, configura-se um adiantamento da divulgação.

A Tabela 2 demonstra o comportamento em dias de postergação ou adiantamento da entrega das informações contábeis em relação à data esperada. 
Tabela 2. Distribuição da postergação/antecipação




Pela análise da Tabela 2, é possível perceber uma evolução significativa no modelo de estimativa de data ao longo dos últimos anos. Em 2010, 20,2\% (18/89) das empresas entregavam as demonstrações contábeis na data esperada. Por outro lado, em 2016, o percentual de entregas na data foi de $28,4 \%$ (315/1.109). No total da amostra, as empresas que entregam as demonstrações na data esperada totalizam $21,1 \%$.

No Gráfico 1, pode ser observada a evolução nos últimos anos relativa à data de entrega das demonstrações contábeis tendo como base a data esperada.

\section{Gráfico 1. Percentual de divulgação na data esperada}

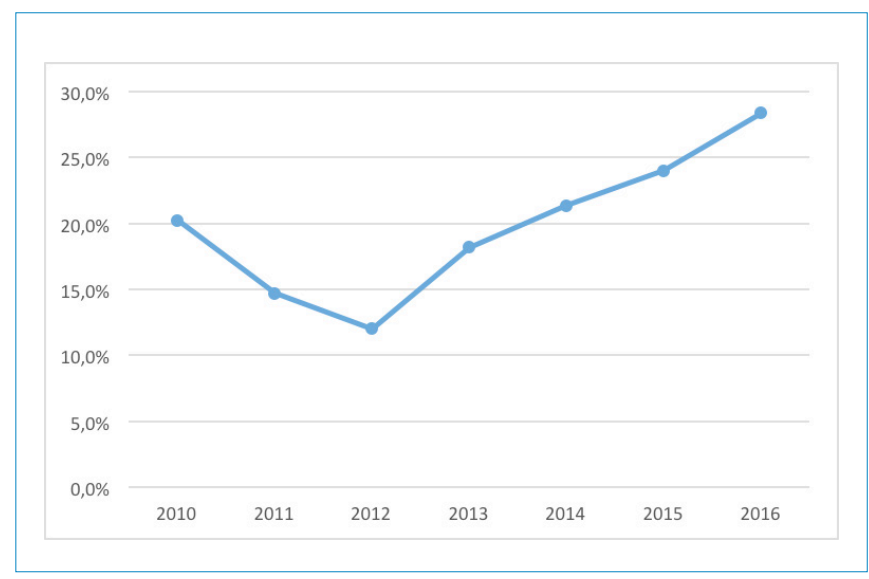

No ano de 2016, o mercado brasileiro comportou-se de maneira muito próxima aos achados de Bagnoli et al. (2002); tal evidência sugere que o mesmo dia da mesma semana do mesmo trimestre do ano anterior é um padrão utilizado por boa parte das empresas brasileiras (28,4\%), assim como das empresas americanas (33,4\%). Uma possível explicação para tal fenômeno é que as firmas tendem a atender um padrão preestabelecido em períodos anteriores, de modo a revelar para os agentes um comprometimento futuro, reduzindo, dessa forma, o nível de assimetria informacional.

Se considerarmos na análise da postergação/adiantamento uma janela de três dias ao redor da data esperada, conclui-se que, mesmo assim, persiste uma evolução significativa no modelo de estimativa utilizado. Em 2010, 21,34\% das empresas entregaram as demonstrações contábeis em torno da data esperada (intervalo de 3 dias, -1 até +1 em relação à data esperada), enquanto em 2016 o percentual de entregas foi de $48,7 \%$. No total da amostra, o percentual de empresas que entregaram nesse intervalo de dias em torno da data esperada foi de 43,9\%. 0 Gráfico 2 demonstra um comportamento aparentemente normal da distribuição relativa a postergação ou adiantamento das empresas no que tange às divulgações das suas respectivas demonstrações contábeis. Tal evidência sugere que a data utilizada como expectativa de entrega da informação contábil ao mercado demonstra ser um padrão no mercado brasileiro.

\section{Gráfico 2. Distribuição referente a postergação e adiantamento da amostra}

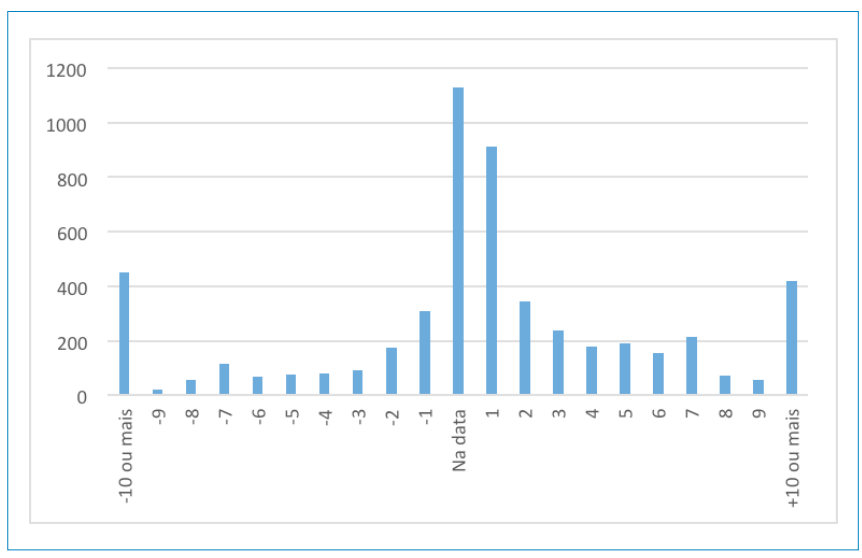

Para testar a hipótese de pesquisa, foram utilizados os modelos: (i) de Mínimos Quadrados Ordinários, como análise principal, e (ii) o modelo Logit, como uma análise de sensibilidade, considerando a variável dependente na forma binária.

Equação 1 (Mínimo Quadrados Ordinários):

POSTERGAÇÃO $=B_{0}+B_{1} S U R P R E S A_{i t}+B_{2} R O A_{i t}+B_{3} P R E J_{i t}+B_{4} L A G_{-} P O S T E R G A C ̧ A O_{i t}$ $+B_{5} D_{E F A S A G E M_{i t}}+B_{6} T A M_{i t}+B_{7} E N D_{i t}+B_{8} G O V_{i t}+B_{9} T R I 4_{i t}+\varepsilon_{i t}$

Equação 2 (Logit - Modelo logístico):

D_POSTERGAÇÃO

$=B_{0}+B_{1} S U R P R E S A_{i t}+B_{2} R O A_{i t}+B_{3} P R E J_{i t}+B_{4} L A G_{-} P O S T E R G A C ̧ A O_{i t}$ $+B_{5} D E F A S A G E M_{i t}+B_{6} T A M_{i t}+B_{7} E N D_{i t}+B_{8} G O V_{i t}+B_{9} T R I 4_{i t}+\varepsilon_{i t}$

A única diferença existente entre os dois modelos apresentados nesta pesquisa está na forma de apresentação da variável dependente, postergação. A variável dependente do modelo 1 POSTERGAÇÃO ${ }_{i t}$ é a diferença de dias entre a data de divulgação e a data esperada de divulgação. A variável dependente do modelo 2 D_POSTERGAÇÃO $O_{i t}$ é uma variável binária, que assume o valor de 1 quando há postergação na entrega das demonstrações contábeis em relação à data esperada e o, em caso contrário. Uma vez que o modelo 2 apresenta uma variável binária como variável dependente, o modelo mais adequado para esse contexto seria o modelo Logit. 
A variável de interesse da pesquisa tipo de notícia SURPRESA $_{i, t}$ representa o tipo de notícia divulgada ao mercado (boa ou má). Essa variável é calculada subtraindo-se o resultado do exercício $t$ pelo resultado do exercício $t$-4, ponderada pelo ativo do período $t$. A divisão pelo ativo é realizada para evitar possíveis distorções na análise, considerando que se espera que empresas de maior porte apresentem maiores resultados em seus relatórios contábeis. Adicionalmente, também rodamos os mesmos modelos substituindo a variável de interesse tipo de notícia por uma variável binária SURPRESA_POS ${ }_{i, t}$ igual a 1 quando a notícia é positiva e o, caso contrário.

Com base na literatura acerca da tempestividade da entrega das informações contábeis, foram incluídas variáveis de controle nos modelos utilizados. Algumas dessas variáveis já foram utilizadas em estudos anteriores realizados no mercado brasileiro em relação à defasagem na entrega das informações (Barcellos et al., 2014; Kirch et al., 2012; Paixão et al., 2017), e demonstraram que efetivamente se relacionam com a data de entrega das demonstrações contábeis.

A variável de controle $P R E J_{i t}$ foi utilizada no modelo devido ao maior nível de dificuldade relacionado à divulgação de prejuízo ao mercado, em vista da maior necessidade de explicação pela administração de resultados negativos (Moreira, Ramos, Kozak-Rogo, \& Rogo, 2016). PREJ jit é uma variável binária, que assume o valor de 1, caso a empresa tenha apresentado prejuízo no período $t$ e o, caso contrário. Com o objetivo de controlar pela complexidade entre companhias, uma vez que existe uma heterogeneidade significativa, o tamanho da firma foi controlado por meio da variável $T A M_{i t}$, que consiste no logaritmo natural do ativo total da empresa no período $t$.

Além disso, foram utilizadas as variáveis $R O A_{i t}, E N D_{i t}, G O V_{i t}$ LAG_POSTERGAÇÃO ${ }_{i t}$, DEFASAGEM ${ }_{i t}$ e TRl $I_{i t}$. A variável $R O A_{i t}$, foi utilizada para controlar a rentabilidade da empresa e foi calculada dividindo-se o resultado apresentado no período $t$ pelo ativo total do período $t$. Já para controle do nível de endividamento de cada companhia, foi empregada a variável $E N D_{i t}$, calculada por meio da divisão das dívidas onerosas brutas pelo ativo total. 0 nível de governança das empresas pode afetar sua probabilidade de evitar a postergação da divulgação de informações, uma vez que as ferramentas de monitoramento podem inibir práticas discricionárias do gestor, como a decisão do momento da divulgação. Nesse sentido, foi utilizada a variável $G O V_{i t}$, que é uma variável binária que recebe o valor 1 , caso a empresa tenha aderido a algum nível diferenciado de governança corporativa (Novo Mercado, Níveis 1 e 2, Bovespa Mais e Bovespa Mais nível 2) e o, caso contrário. 0 comportamento passado da firma pode explicar em partes o seu comportamento atual, dessa forma foi incluída a variável LAG_POSTERGAÇÃO $O_{i t}$, a qual é uma variável que assume valor igual a 1 se a empresa postergou a entrega da demonstração contábil no período anterior e o, caso contrário. A variável DEFASAGEM ${ }_{i t}$, por sua vez, foi calculada pelo número de dias corridos da data base das demonstrações contábeis até a data da divulgação. Foi utilizada como controle, pois acredita-se que empresas com maior defasagem (número de dias corridos entre a data base das demonstrações contábeis e a data de divulgação) apresentem maior probabilidade de atrasar a entrega das informações aos participantes do mercado. A variável $T R / 4_{i t}$, que assume valor igual a 1 se a informação for referente ao quarto trimestre e o, caso contrário, foi adicionada para controlar potenciais diferenças existentes na entrega de informações trimestrais para entrega de informações anuais.

Com o objetivo de controlar os efeitos fixos de ano e setor, foram incluídas variáveis indicadoras para cada ano e setor em ambos os modelos utilizados na pesquisa. Além disso, os dois modelos abordados nesta pesquisa foram rodados com matriz de erro robusta para melhor tratamento estatístico.

\section{ANÁLISE DOS RESULTADOS}

Na Tabela 3, são apresentadas as estatísticas descritivas das variáveis utilizadas nos dois modelos. Todas as variáveis contínuas foram winsorizadas aos níveis 1\% e $99 \%$ para tratar possiveis outliers existentes na amostra e que prejudicam as análises estatísticas, caso não sejam devidamente tratados.

É possível observar na Tabela 3 que, em média, as empresas divulgam suas demonstrações contábeis aproximadamente de dois a três dias antes da data esperada, e que a defasagem média para divulgação dessas demonstrações é de aproximadamente 52 dias. A defasagem média de 52 dias na amostra é impactada tanto pelo prazo máximo de divulgação das informações trimestrais de 45 dias corridos após a data base quanto pelo prazo máximo da divulgação das demonstrações contábeis anuais, de 90 dias corridos após a data base, conforme determinado pela Comissão de Valores Mobiliários (CVM) por meio da Instrução CVM no 480/2009. Em torno de $52 \%$ das empresas que compõem a amostra postergam a entrega da divulgação da informação contábil. Apesar de ser um número relevante, cumpre destacar que isso não significa que as empresas entreguem fora do período exigido pela CVM. Nos últimos cinco anos, é observado um percentual cada vez maior de empresas que entregam a informação contábil até a data esperada: no ano de $2012,45 \%$ e, no ano de $2016,55 \%$ das empresas. 
Tabela 3. Estatística descritiva

\begin{tabular}{|c|c|c|c|c|c|}
\hline Variáveis & Observações & Média & Desvio Padrão & Mínimo & Máximo \\
\hline POSTERGAÇÃO & 5356 & $-2,666$ & 31,132 & $-243,000$ & 84,000 \\
\hline D_POSTERGAÇÃO & 5356 & 0,512 & 0,500 & 0,000 & 1,000 \\
\hline SURPRESA & 5356 & 0,006 & 0,319 & $-1,429$ & 2,188 \\
\hline SUPRESA_POS & 5356 & 0,479 & 0,500 & 0,000 & 1,000 \\
\hline ROA & 5356 & $-0,168$ & 0,834 & $-0,643$ & 0,215 \\
\hline TAM & 5356 & 13,497 & 3,134 & 2,887 & 18,443 \\
\hline END & 5356 & 1,444 & 4,720 & 0,001 & 39,333 \\
\hline GOV & 5356 & 0,409 & 0,492 & 0,000 & 1,000 \\
\hline TRI4 & 5356 & 0,229 & 0,420 & 0,000 & 1,000 \\
\hline
\end{tabular}

POSTERGAÇ̃̃O é o número de dias adiantado (-) ou postergado (+) em relação à data esperada de divulgação. D_POSTERGAÇÃO é uma variável dummy que assume 1 quando houve postergação na entrega das demonstrações contábeis e o, caso contrário. DEFASAGEM é o logaritmo do número de dias corridos da data base das Demonstrações Contábeis até a data da divulgação. SURPRESA representa o tipo de notícia e é calculada subtraindo o resultado do exercício t pelo exercício t-1 ponderada pelo ativo do período t. SURPRESA_POS é uma variável dummy que assume 1 quando a surpresa é positiva e o, caso contrário. ROA é o lucro líquido da empresa no período t dividido pelo ativo total do período t. PREJ é uma variável dummy que assume 1, caso a empresa tenha apresentado prejuízo no período te o, caso contrário. TAM é o logaritmo natural do ativo total da empresa no período t. END é o total de dívidas brutas da empresa t dividido pelo ativo total no período t. GOV é uma variável dummy igual a 1, caso a empresa tenha algum nível diferenciado de governança corporativa e o, caso contrário. TR/4 é uma variável dummy igual a 1, caso seja o $4^{\circ}$ trimestre e o, caso contrário. Todas as variáveis contínuas foram winsorizadas aos níveis de $1 \%$ e $99 \%$.

Aproximadamente $48 \%$ das empresas apresentam uma boa notícia para o mercado. Nota-se também, ainda na Tabela 3 , que a média da variável $P R E J_{i t}$, é de aproximadamente 0,38 . Por ser uma variável binária, conclui-se que aproximadamente $38 \%$ das observações da amostra são de empresas que reportaram prejuízo, e os outros $62 \%$ são de empresas que apresentaram resultado maior ou igual a zero. Analisando a variável binária $G O V_{i t}$ é possível notar que aproximadamente $40 \%$ das observações da amostra são de empresas que possuem algum nível diferenciado de governança corporativa.

$\mathrm{Na}$ Tabela 4, são apresentadas as correlações entre as variáveis utilizadas nos dois modelos da pesquisa.

\section{Tabela 4. Matriz de correlação}

\begin{tabular}{|c|c|c|c|c|c|c|c|c|c|c|c|}
\hline & 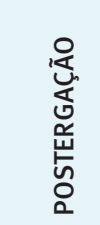 & 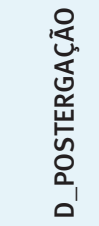 & 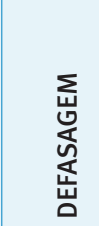 & 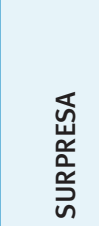 & 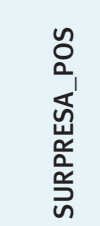 & ర్ & 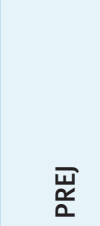 & $\sum_{\mathbb{1}}$ & 主 & 어 & $\frac{\text { q }}{\underline{\underline{\alpha}}}$ \\
\hline POSTERGAÇÃO & 1,000 & & & & & & & & & & \\
\hline D_POSTERGAÇÃO & 0,321 & 1,000 & & & & & & & & & \\
\hline DEFASAGEM & $-0,008$ & 0,130 & 1,000 & & & & & & & & \\
\hline SURPRESA & $-0,051$ & $-0,034$ & 0,025 & 1,000 & & & & & & & \\
\hline SURPRESA_POS & $-0,036$ & $-0,059$ & $-0,034$ & 0,310 & 1,000 & & & & & & \\
\hline ROA & $-0,012$ & $-0,027$ & $-0,087$ & 0,076 & 0,084 & 1,000 & & & & & \\
\hline PREJ & 0,039 & $-0,065$ & $-0,189$ & 0,048 & 0,279 & 0,307 & 1,000 & & & & \\
\hline TAM & 0,038 & $-0,050$ & $-0,142$ & $-0,053$ & 0,012 & 0,551 & 0,371 & 1,000 & & & \\
\hline END & $-0,044$ & 0,011 & 0,068 & 0,036 & $-0,023$ & $-0,067$ & $-0,108$ & 0,087 & 1,000 & & \\
\hline GOV & 0,017 & $-0,063$ & $-0,217$ & 0,006 & 0,022 & 0,158 & 0,181 & 0,432 & $-0,001$ & 1,000 & \\
\hline TRI4 & 0,025 & $-0,037$ & 0,620 & 0,004 & 0,013 & $-0,047$ & 0,017 & $-0,015$ & $-0,001$ & $-0,024$ & 1,000 \\
\hline
\end{tabular}

POSTERGAÇÃO é o número de dias adiantado (-) ou postergado (+) em relação à data esperada de divulgação. D_POSTERGAÇÃO é uma variável dummy que assume 1 quando houve postergação na entrega das demonstrações contábeis e o, caso contrário. DEFASAGEM é o logaritmo do número de dias corridos da data base das Demonstrações Contábeis até a data da divulgação. SURPRESA representa o tipo de notícia e é calculada subtraindo o resultado do exercício t pelo exercício t-1 ponderada pelo ativo do período t. SURPRESA_POS é uma variável dummy que assume 1 quando a surpresa é positiva e o, caso contrário. ROA é o lucro líquido da empresa no período t dividido pelo ativo total do período t. PREJ é uma variável dummy que assume 1, caso a empresa tenha apresentado prejuízo no período t e o, caso contrário. TAM é o logaritmo natural do ativo total da empresa no período t. END é o total de dívidas brutas da empresa t dividido pelo ativo total no período t. GOV é uma variável dummy igual a 1, caso a empresa tenha algum nível diferenciado de governança corporativa e o, caso contrário. TRI 4 é uma variável dummy igual a 1, caso seja $04^{0}$ trimestre e o, caso contrário. Todas as variáveis contínuas foram winsorizadas aos níveis de $1 \%$ e $99 \%$. * representam coeficientes estatisticamente significativos ao nível de pelo menos o,10. 
Por meio da análise de correlação, é possível observar que existe uma associação negativa entre as variáveis de postergação (POSTERGAÇÃO e D_POSTERGAÇÃO) e as variáveis de tipo de notícia (SURPRESA e SURPRESA_POS), indicando que notícia boas estão mais relacionadas à antecipação da informação contábil. Tal evidência está em linha com a hipótese de pesquisa apresentada neste estudo, entretanto a correlação é apenas uma análise preliminar de associação entre as duas variáveis, sem o tratamento devido das variáveis de controle.
$\mathrm{Na}$ Tabela 5, são apresentadas as relações entre a postergação/antecipação na entrega das demonstrações contábeis e o tipo de notícia. Nas duas primeiras colunas de resultados, são apresentados os coeficientes estatísticos para o modelo 1 , estando na primeira coluna a variável de interesse tipo de notícia na forma contínua (SURPRESA) e na segunda coluna na forma binária (SURPRESA_POS). Na terceira e quarta colunas, são apresentados os resultados referentes ao modelo 2; da mesma maneira, na terceira coluna, a variável de interesse na forma contínua e na quarta coluna na forma binária.

Tabela 5. Relação entre o tipo de notícia e o atraso na data de entrega

\begin{tabular}{|c|c|c|c|c|c|c|c|c|c|c|c|c|}
\hline $\begin{array}{l}\text { Variáveis } \\
\text { Independentes }\end{array}$ & $\begin{array}{c}\text { Coeficiente } \\
-4,239\end{array}$ & \multicolumn{2}{|c|}{ t-estatística } & Coeficiente & \multicolumn{2}{|c|}{ t-estatística } & $\begin{array}{c}\text { Coeficiente } \\
-0,221\end{array}$ & \multicolumn{2}{|c|}{ z-estatística } & Coeficiente & \multicolumn{2}{|c|}{ z-estatística } \\
\hline SUPRESA_POS & & & & $-2,174$ & $-2,510$ & $\star \star$ & & & & $-0,157$ & $-2,600$ & $\star \star *$ \\
\hline PREJ & 3,620 & 3,850 & 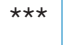 & 4,081 & 4,320 & 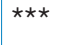 & $-0,022$ & $-0,340$ & & 0,016 & 0,230 & \\
\hline LAG_POSTERGAÇÃO & 9,099 & 10,160 & $\star \star \star *$ & 9,143 & 10,160 & $\star \star \star \star$ & 0,537 & 9,320 & 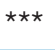 & 0,537 & 9,310 & $\star \star \star *$ \\
\hline DEFASAGEM & 0,866 & 0,200 & & 0,733 & 0,170 & & 1,656 & 9,220 & 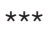 & 1,647 & 9,170 & 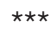 \\
\hline GOV & 0,096 & 0,090 & & $-0,036$ & $-0,030$ & & 0,003 & 0,040 & & $-0,003$ & $-0,050$ & \\
\hline TRI4 & 3,192 & 1,140 & & 3,247 & 1,150 & & $-1,103$ & $-8,340$ & $* * *$ & $-1,099$ & $-8,300$ & $* * *$ \\
\hline Constante & $-40,900$ & $-2,240$ & $\star \star$ & $-39,785$ & $-2,160$ & $\star \star$ & $-7,619$ & $-8,870$ & $\star \star \star$ & $-7,523$ & $-8,740$ & $\star \star \star$ \\
\hline Efeito fixo ano & Sim & & & Sim & & & Sim & & & Sim & & \\
\hline Efeito fixo setor & Sim & & & Sim & & & Sim & & & $\operatorname{Sim}$ & & \\
\hline Observações & 5356 & & & 5356 & & & 5356 & & & 5356 & & \\
\hline R2 ou Pseudo R2 & 0,079 & & & 0,078 & & & 0,062 & & & 0,062 & & \\
\hline
\end{tabular}

POSTERGAÇÃO é o número de dias adiantado (-) ou postergado (+) em relação à data esperada de divulgação. D_POSTERGAÇ̃̃o é uma variável dummy que assume 1 quando houve postergação na entrega das demonstrações contábeis e o, caso contrário. SURPRESA representa o tipo de notícia e é calculada subtraindo o resultado do exercício t pelo exercício t-1 ponderada pelo ativo do período t. SURPRESA_POS é uma variável dummy que assume 1 quando a surpresa é positiva e o, caso contrário. ROA é o lucro líquido da empresa no período t dividido pelo ativo total do período t. PREJ é uma variável dummy que assume 1 caso a empresa tenha apresentado prejuízo no período te o, caso contrário. LAG_POSTERGAÇÃO é uma variável dummy que assume o valor de 1, caso a empresa tenha postergado a entrega das demonstrações contáveis no trimestre anterior e o, caso contrário. DEFASAGEM é o logaritmo do número de dias corridos da data base das Demonstrações Contábeis até a data da divulgação. TAM é o logaritmo natural do ativo total da empresa no período t. END é o total de dívidas brutas da empresa t dividido pelo ativo total no período t. GOV é uma variável dummy igual a 1, caso a empresa tenha algum nível diferenciado de governança corporativa e o, caso contrário. TRI 4 é uma variável dummy igual a 1, caso seja $04^{\circ}$ trimestre e 0 ,

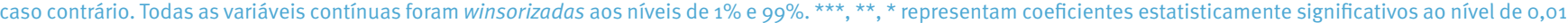
0,05 e 0,10 , respectivamente.

Para avaliar a hipótese de pesquisa utilizada neste estudo, de que empresas com más notícias postergam a divulgação das informações contábeis em relação às datas esperadas, analisamos a variável SURPRESA, que representa o tipo de notícia contada ao mercado. Os resultados apresentados na Tabela 5 indicam que o coeficiente da variável SURPRESA é negativo e estatisticamente 
significativo a pelo menos $95 \%$ de confiança nos dois modelos. No modelo 1, usando a variável tipo de notícia na forma contínua (SURPRESA) ou na forma binária (SURPRESA_POS), foram encontradas evidências de que, em média, as empresas antecipam as boas notícias entre dois e quatro dias. Com base no modelo 2, os resultados mostram evidências na mesma direção, ou seja, que, se a notícia a ser contada para o mercado é boa, diminui a probabilidade de a empresa postergar a entrega da informação.

Tais evidências estão em linha com resultados encontrados por Bagnoli et al. (2002), que analisaram o desempenho das empresas em que a administração ultrapassa sua própria data esperada de divulgação.

Adicionalmente, foram encontradas evidências de que, se a firma postergou a entrega da informação contábil no período anterior, aumenta a probabilidade de ela postergar no período atual. Tal relação sugere que, quando a firma quebra um padrão esperado pelo mercado, aumentam as chances de ela voltar a repetir o mesmo comportamento. Em relação às demais medidas de performance, no modelo 1 , foram encontradas evidências de que empresas com prejuízo tendem a postergar mais a entrega das demonstrações financeiras e que quanto maior o retorno do ativo, mais as empresas antecipam a divulgação da notícia. Tais evidências estão em linha com a ideia de que boas notícias têm maior probabilidade de serem antecipadas e más notícias, maior probabilidade de serem postergadas.

0 tamanho da empresa, segundo resultados apresentados pelo modelo 1, também exerce influência sobre o prazo de entrega da informação contábil: quanto maior a empresa, maior o tempo de postergação da entrega da informação contábil. É provável que tal evidência esteja relacionada com a complexidade da empresa, o que, de certa forma, pode influenciar o momento em que a informação contábil está apta a ser divulgada para o mercado. No modelo 2, a referida relação do tamanho da empresa não foi estatisticamente significativa.

O nível de endividamento da empresa também sugere exercer uma influência estatisticamente significativa no momento em que a firma entrega a demonstração contábil. Com base no modelo 1, foram encontradas evidências de que quanto mais endividada a empresa é, mais rápido ela divulga a notícia. Essa evidência pode estar relacionada com o fato de o mercado já conhecer antecipadamente o nível de endividamento da empresa, uma vez que a variação de um trimestre para outro tende a ser baixa, logo a empresa opta por antecipar a divulgação da notícia assumindo que o mercado já possui essa informação. No modelo 2, não foram encontradas evidências estatisticamente significativas dessa relação.
Tanto a defasagem, ou seja, o tempo em que a empresa demora para entregar a informação contábil, contada a partir do final do exercício social, quanto o fato de a informação ser uma demonstração contábil anual também influenciam a probabilidade de a empresa postergar a divulgação do relatório. Com base nos resultados do modelo 2, quanto maior a defasagem, maior a probabilidade de postergar a entrega da informação contábil. É razoável esperar tal comportamento, uma vez que quanto mais dias corridos a empresa demora para entregar a informação, maior a chance de ultrapassar a data esperada da divulgação. Já em relação ao quarto trimestre, os resultados do modelo 2 sugerem que é menor a probabilidade de as empresas postergarem a entregam da informação contábil quando comparada com as informações trimestrais. Tal evidência também é compreensível uma vez que a informação anual tende a ser uma informação mais importante e mais esperada pelo mercado, e provavelmente atrasar tal informação poderia gerar um impacto ainda mais negativo para a empresa.

No que tange a governança corporativa, não foram encontradas evidências estatisticamente significativas de que essa variável exerça influência sobre a postergação da divulgação da informação contábil. Era esperado que o maior nível de monitoramento influenciasse o prazo de divulgação da informação contábil. Entretanto, tal relação não foi observada e pode estar associada à fragilidade da proxy de capturar os verdadeiros níveis de governança corporativa das empresas.

\section{ANÁLISES ADICIONAIS}

Duas análises adicionais foram realizadas com objetivo de verificar o efeito sobre os resultados anteriores. A primeira análise foi restringir a amostra apenas às informações anuais, uma vez que essas informações podem ser vistas como mais importantes do que as trimestrais e, assim, demonstrar um comportamento diferente da firma. Os resultados se mantiveram inalterados, conforme observado na Tabela 6 (Painel A), ou seja, notícias boas são, em média, antecipadas entre quatro e cinco dias em relação à data esperada de divulgação.

A segunda análise foi baseada na alteração da variável binária de postergação ( $\left.D \_P O S T E R G A C ̧ A ̃ O\right)$ e, consequentemente, na de reincidência de postergação ( $\left.L A G \_P O S T E R G A C ̧ A ̃ O\right)$ para um dia a mais do que as variáveis originais. Portanto, as variáveis binárias D_POSTERGAÇÃ (2) e LAG_POSTERGAÇÃO (2) são iguais a 1 quando a firma entregou a informação na data esperada (o) ou até um dia de postergação (+1) e zero, caso contrário. Dessa forma, ampliamos em um dia o prazo esperado de entrega, ou 
seja, diminuímos o número de empresas com postergação da informação contábil. Os resultados, conforme Tabela 6 (Painel B), se mantiveram em grande maioria inalterados, mantendo evidências na direção de que o tipo de notícias a ser divulgado boa notícia (má notícia) está relacionado com a antecipação (postergação) da divulgação das demonstrações financeiras.

\section{Tabela 6. Relação entre o prazo de entrega e o tipo de notícia (testes de robustez)}

\begin{tabular}{|c|c|c|c|c|c|c|c|c|c|c|c|c|}
\hline \multicolumn{13}{|c|}{ Painel A: Robustez informações anuais } \\
\hline $\begin{array}{l}\text { Variáveis } \\
\text { Independentes }\end{array}$ & $\begin{array}{c}\text { Coeficiente } \\
-4,172\end{array}$ & $-3,090$ & $\star \star \star \star ~$ & Coeficiente & & & $\begin{array}{c}\text { Coeficiente } \\
-0,304\end{array}$ & $-1,890$ & * & Coeficiente & & \\
\hline SUPRESA_POS & & & & $-5,686$ & $-3,660$ & *** & & & & $-0,473$ & $-3,630$ & $\star \star \star ~$ \\
\hline Efeito fixo ano & Sim & & & Sim & & & Sim & & & Sim & & \\
\hline Efeito fixo setor & Sim & & & Sim & & & Sim & & & Sim & & \\
\hline Observações & 1225 & & & 1225 & & & 1217 & & & 1217 & & \\
\hline \multirow{2}{*}{$\begin{array}{l}\text { Variáveis } \\
\text { Independentes }\end{array}$} & \multicolumn{3}{|c|}{ [a] POSTERGAÇÃO } & \multicolumn{3}{|c|}{ [a] POSTERGAÇÃO } & \multicolumn{3}{|c|}{ [b] D_POSTERGAÇÃO (2) } & \multicolumn{3}{|c|}{ [b] D_POSTERGAÇÃO (2) } \\
\hline & Coeficiente & \multicolumn{2}{|c|}{ t-estatística } & Coeficiente & \multicolumn{2}{|c|}{ t-estatística } & Coeficiente & \multicolumn{2}{|c|}{ z-estatística } & Coeficiente & \multicolumn{2}{|c|}{ z-estatística } \\
\hline SURPRESA & $-4,458$ & $-2,460$ & $\star \star$ & & & & $-0,164$ & $-1,550$ & & & & \\
\hline SUPRESA_POS & & & & $-2,253$ & $-2,590$ & $\star \star$ & & & & $-0,189$ & $-2,970$ & $\star \star \star ~$ \\
\hline LAG_POSTERGAÇÃO (2) & 8,293 & 10,080 & $\star \star \star$ & 8,321 & 10,060 & $\star \star \star$ & 0,587 & 9,410 & $\star \star \star$ & 0,584 & 9,360 & $\star \star \star ~$ \\
\hline Controles & Sim & & & Sim & & & Sim & & & Sim & & \\
\hline Efeito fixo ano & Sim & & & Sim & & & Sim & & & Sim & & \\
\hline
\end{tabular}

POSTERGAÇÃO é o número de dias adiantado (-) ou postergado (+) em relação à data esperada de divulgação. D_POSTERGAÇÃo (2) é uma variável dummy que assume 1 quando houve postergação na entrega das demonstrações contábeis e o, caso contrário. SURPRESA representa o tipo de notícia e é calculada subtraindo o resultado do exercício t pelo exercício t-1 ponderada pelo ativo do período t. SURPRESA_POS é uma variável dummy que assume 1 quando a surpresa é positiva e o, caso contrário. LAG_POSTERGAÇÃO (2) é uma variável dummy que assume o valor de 1, caso a empresa tenha postergado a entrega das demonstrações contáveis no trimestre anterior e o, caso contrário. Todas as variáveis contínuas foram winsorizadas aos níveis de $1 \%$ e $99 \%$. ***, ** * representam coeficientes estatisticamente significativos ao nível de $0,01,0,05$ e 0,10 , respectivamente.

\section{CONCLUSÃO}

O presente estudo buscou analisar a relação entre a antecipação/postergação da informação contábil com o tipo de notícia a ser divulgada para o mercado. De modo geral, os resultados sugerem que quando a empresa tem uma má (boa) notícia para comunicar ao mercado, existe uma maior probabilidade de a empresa postergar (antecipar) essa divulgação.

As evidências encontradas trazem implicações importantes para a literatura de evidenciação nacional, bem como para o mercado de capitais brasileiro. Em relação à literatura nacional, foi possível diagnosticar que, assim como no mercado americano, as empresas brasileiras seguem um padrão de data esperada de divulgação da informação contábil que é possível de ser captado por um 
modelo de estimativa (naive model). Dessa forma, contribui com evidências empíricas relacionadas à Teoria da Divulgação no que tange ao comportamento da firma em relação à tempestividade da entrega das demonstrações financeiras no mercado brasileiro.

Em relação ao mercado de capitais, a pesquisa contribui mostrando evidências de que as empresas, em média, atendem as exigências da CVM em relação ao prazo máximo de entrega das demonstrações contábeis, porém aproximadamente metade das empresas brasileiras não é tempestiva na entrega da informação contábil em relação à data esperada pelo mercado. Aparentemente, nos últimos anos, as empresas estão se preocupando mais com a divulgação de maneira tempestiva, respeitando o padrão de divulgação esperado, provavelmente como forma de atender as expectativas dos agentes de mercado, o que sinaliza um possível desenvolvimento do mercado de capitais brasileiro.

As limitações desta pesquisa estão principalmente relacionadas às proxies utilizadas para cálculo da antecipação/ postergação da informação contábil, bem como pela definição de boa ou má notícia, apesar de ambas as proxies estarem baseadas em trabalhos na literatura internacional. A inexistência de base histórica com expectativa dos participantes do mercado em relação à data de divulgação também representa uma limitação da pesquisa, sendo possível apenas a aplicação de modelos de estimativa (naive model). Adicionalmente, os resultados desta pesquisa limitam-se a um comportamento do mercado de capitais brasileiro no período de 2010 a 2016.

Ademais, sugere-se, para pesquisas futuras, que estudem o efeito de outros potenciais determinantes na postergação da entrega das demonstrações contábeis, como gerenciamento de resultados e mecanismos de monitoramento. Sugere-se, também, a realização de estudos com outros modelos de estimativa de data de divulgação ou de previsões do mercado, como a utilização do calendário de eventos corporativos. Por fim, seriam interessantes também novos estudos relacionados às consequências da postergação na entrega da informação contábil, bem como estudos relacionados à reação de mercado no momento da divulgação das demonstrações financeiras.

\section{NOTA DOS AUTORES}

O artigo é originado da dissertação de mestrado do autor Anderson Brito Vivas, que foi orientada pelo autor Felipe Ramos Ferreira, e teve como um dos membros da banca de defesa o autor Fábio Moraes da Costa.

\section{REFERÊNCIAS}

Bagnoli, M., Kross, W., \& Watts, S. G. (2002). The information in management's expected earnings report date: A day late, a penny short. Journal of Accounting Research, 40(5), 1275-1296. doi: 10.1111/1475-679X.to1-1-00054

Barcellos, L. P., Costa, J. V., Júnior, \& Laurence, L. C. (2014). Determinantes do prazo de divulgação das demonstrações contábeis das companhias não financeiras listadas na Bovespa. Revista de Contabilidade e Organizações, 8(20), 84-100. doi: 10.11606/rco. v8i20.69265

Begley, J., \& Fischer, P. (1998). Is there information in an earnings announcement delay? Review of Accounting Studies, 3, 347-363. doi: 10.1023/A:1009635117801

Beyer, A., Cohen, D. A., Lys, T. Z., \& Walther, B. R. (2010). The financial reporting environment: Review of the recent literature. Journal of Accounting and Economics, 50(2), 296-343. doi: 10.1016/j. jacceco.2010.10.003

Boulland, R. \& Dessaint, O. (2017). Announcing the announcement. Journal of Banking \& Finance, 82, 59-79. doi: 10.1016/j. jbankfin.2017.05.007

Chen, G., Cheng, L. T. W., \& Gao, N. (2005). Information content and timing of earnings announcements. Journal of Business Finance \& Accounting, 32(1-2), 65-95. doi: 10.1111/j.0306-686X.2005.00588.x

Dantas, J. A., Zendersky, H. C., Santos, S. C., \& Niyama, J. K. (2008). A dualidade entre os benefícios do disclosure e a relutância das organizações em aumentar o grau de evidenciação. Economia \& Gestão, 5(11), 56-76. Recuperado de http://periodicos.pucminas.br/ index.php/economiaegestao/article/view/40/34

Dye, R. (2001). Na evaluation of "essays on disclosure" and the disclosure literature in accounting. Journal of Accounting \& Economics, 32, 181-235. doi: 10.1016/S0165-4101(01)00024-6

Givoly, D., \& Palmon, D. (1982). Timeliness of annual earnings announcements: Some empirical evidence. The Accounting Review, 57(3), 486-508. Recuperado de https://www.jstor.org/stable/246875

Graham, J. R., Harvey, C. R., \& Rajgopal, S. (2005). The economic implications of corporate financial reporting. Journal of Accounting and Economics, 40(1), 3-73. doi: 10.1016/j.jacceco.2005.01.002

Haw, I. M., Qi, D., \& Wu, W. (2000). Timeliness of annual report releases and market reaction to earnings announcements in an emerging capital market: The case of China. Journal of International Financial Management \& Accounting, 11(2), 108-131. doi: 10.1111/1467$646 \mathrm{X} .00058$

Healy, P. M., \& Palepu, K. G. (2001). Information asymmetry, corporate disclosure, and the capital markets: A review of the empirical disclosure literature. Journal of Accounting and Economics, 31(1), 405-440. doi: 10.1016/S0165-4101(01)00018-0

Kirch, G., Lima, J. B. N., \& Terra, P. R. S. (2012). Determinantes da defasagem na divulgação das demonstrações contábeis das companhias abertas brasileiras. Revista Contabilidade \& Finanças, 23(60), 173-186. doi: 10.1590/S1519-70772012000300003

Kross, W., \& Schroeder, D. A. (1984). An empirical investigation of the effect of quarterly earnings announcement timing on stock returns. Journal of Accounting Research, 22(1), 153-176. doi: $10.2307 / 2490706$ 
Moreira, N. C., Ramos, F., Kozak-Rogo, J., \& Rogo, R. (2016). Conference calls: An empirical analysis of information content and the type of disclosed news. BBR. Brazilian Business Review, 13(6), 291-315. doi: 10.15728/bbr.2016.13.6.6

Paixão, L. M. D., Avelino, B. C., \& Takamatsu, R. T. (2017). Determinantes do momento de divulgação das demonstrações contábeis de empresas que compõem o Índice da Bolsa de Valores de São Paulo (Ibovespa). Revista de Contabilidade \& Controladoria, 9(1), 47-66. doi: $10.5380 /$ rcc.vgi1.47940
Sengupta, P. (2004). Disclosure timing: Determinants of quarterly earnings release dates. Journal of Accounting and Public Policy, 23(6), 457-482. doi: 10.1016/j.jaccpubpol.2004.10.001

Trueman, B. (1990). Theories of earnings-announcement timing. Journal of Accounting and Economics, 13(3), 285-301. doi: 10.1016/01654101(90)90035-3

Verrecchia, R. (2001). Essays on disclosure. Journal of Accounting \& Economics, 32, 97-180. doi: 10.1016/S0165-4101(01)00025-8

\section{CONTRIBUIÇÃO DOS AUTORES}

O autor Anderson Brito Vivas contribuiu em todas as partes do artigo, desde a revisão teórica, coleta e análise dos dados bem como a redação. 0 autor Felipe Ramos Ferreira trabalhou na concepção da ideia, design metodológico, análise dos dados e redação. Por fim, o autor Fábio Moraes da Costa, trabalhou em análise adicionais com testes de robustez, redação e revisão final. 